\title{
IFIP working groups and the scope of EAIT articles
}

\author{
Arthur Tatnall
}

Published online: 3 February 2010

C) Springer Science+Business Media, LLC 2010

The Journal of Education and Information Technologies (EAIT) is the official research outlet for IFIP TC3. The International Federation for Information Processing (IFIP) is the world peak body for Information and Communications Technologies (ICT) and its membership includes computing societies from many countries around the world. IFIP is organised around 13 Technical Committees and TC3 is the group concerned with Computing and Education. Each TC is further subdivided into a number of Working Groups and Special Interest Groups. The Working Groups that comprise TC3 are:

WG3.1 Secondary Education

WG3.2 Higher Education

WG3.3 Research

WG3.4 Professional and Vocational Education

WG3.5 Primary Education

WG3.6 Distance Education

WG3.7 Educational Management

WG3.8 Lifelong Learning

SIG3.9 Digital Literacy

Since taking over as Editor-in-Chief of EAIT a few months ago I have noted that although the coverage of articles we receive is quite wide, there are some significant missing topics. The Journal's mission notes that is should be:

... a platform for the range of debates and issues that are current in our field. It is a broad field; we aim to provide perspectives at all levels, from the micro of specific applications or instances of use in classrooms to macro concerns of national policies and major projects; from classes of 5 year olds to adults in tertiary institutions; from teachers and administrators, to researchers and designers; from institutions to open, distance and lifelong learning. The

\footnotetext{
A. Tatnall $(\bowtie)$

Victoria University, Melbourne, Australia

e-mail: Arthur.Tatnall@vu.edu.au
} 
strength of this breadth lies in the opportunity to raise and debate fundamental issues at all levels, to discuss specific instances and cases, draw inference and probe theory. This journal is embedded in the research and practice of professionals. It will not proselytise on behalf of the technologies but rather provoke debate on all the complex relationships between information and communication technologies and education.

Using TC3's list of Working Groups as a guide it would be good to see a wider range of articles submitted in the future to cover all the various aspects of ICT and Education. I should note however that the journal's mission relates to Education and ICT and that in future, general education articles that contain only passing reference to ICT will not be accepted.

The first article in this issue is by Michail Kalogiannakis from the University of Crete, Greece. It is titled: Training with ICT for ICT from the trainee's perspective. A local ICT teacher training experience. The article describes research resulting from an exploratory study conducted within the framework of a national ICT training programme in Greece ("In-service teacher training in the use of ICT in Education").

Next comes an article on: The finite element method magnetics (FEMM) freeware package: May it serve as an educational tool in teaching electromagnetics? by Konstantinos B. Baltzis from the Aristotle University of Thessaloniki, Greece. This paper explores the capability of FEMM to act as a complementary tool for teaching electromagnetics in higher education.

The next article: A trio of evaluation and assessment models from pre ICT innovations: Lessons from the past is by Gail Marshall from the USA. The article describes three major evaluations of innovative projects designed and implemented in the US during the 1960s and 1970s. Marshall argues that these evaluations can provide good models for the design and analysis of ICT projects that can serve ICT educators as guidelines for complex, meaningful and educationally sound ways of determining the impact of ICT on all stakeholders.

In the final article: Structural and conceptual user interfaces and their impact on learning, David Passig and Liav Nadler from Bar-Ilan University in Israel, describe a study that examined the impact of structural and conceptual user interfaces on learning among High School students. They found that the interlacing of interfaces by itself does not contribute to learning, but that interlacing of specific, compatible interfaces makes navigation easier and also enhances deep understanding of content.

I look forward in the future to receiving many more different articles covering the wide range of topics that make up Education and Information Technologies. 